\title{
Upper extremity deep venous thrombosis secondary to thyrotoxic periodic paralysis with accompanying hyperphosphatemia and severe hypomagnesemia
}

\author{
Jasmin Rahesh MS, MBA, Layan AI-Sukhni BS, Baseer Quraishi BS, Tarek Naguib MD
}

\begin{abstract}
Thyrotoxic periodic paralysis is a rare but life-threatening complication of hyperthyroidism. Characteristic features include thyrotoxicosis, acute paralysis, and hypokalemia. Mild hypomagnesemia and hypophosphatemia are also present in most cases due to the transcellular shift of electrolytes. Complications of thyrotoxic periodic paralysis reported in the literature have included cerebral venous thrombosis and lower extremity deep venous thrombosis. We present a patient with an unusual presentation of thyrotoxic periodic paralysis with hyperphosphatemia, upper extremity deep venous thrombosis, and severe hypomagnesemia. This is the first reported case of upper extremity deep vein thrombosis in association with a peripherally inserted central catheter line secondary to thyrotoxicosis.
\end{abstract}

Keywords: thyrotoxic periodic paralysis, deep venous thrombosis

\section{INTRODUCTION}

Thyrotoxic periodic paralysis (TPP) is a serious complication of hyperthyroidism that is most commonly seen in men between the ages of 20 to $40 .^{1}$ Thyrotoxic periodic paralysis presents with hypokalemia and acute onset proximal muscle weakness in the lower extremities that can last for 3-96 hours. ${ }^{2,3}$ Other findings of hyperthyroidism, such as tachycardia, warm and moist skin, and fever can also develop. Initial treatment involves potassium supplementation to prevent the complications of hypokalemia. Definitive treatment includes managing the underlying thyroid disorder with antithyroid medication and in some cases possible thyroidectomy or radioiodine ablation. ${ }^{2}$

\section{CASE}

A 20-year-old man with history of drug abuse and osteochondritis presented to the emergency

Corresponding author: Jasmin Rahesh Contact Information: Jasmin.rahesh@ttuhsc.edu DOI: 10.12746/swrccc.v9i41.927 department (ED) with bilateral leg weakness and foot numbness. That morning he woke up unable to move his legs or his back and fell out of bed, after which he noticed that he had feeling in his legs but not his feet. He was found to be profoundly hypokalemic at $1.6 \mathrm{mmol} / \mathrm{L}$ and hypomagnesemic at $1.5 \mathrm{mg} / \mathrm{dL}$. Phosphate levels were not taken at this time, but calcium was $9.0 \mathrm{mg} / \mathrm{dL}$. These values were verified by a redraw and repeat chemistry. The patient denied nausea, vomiting, and diuretic use but did report loose bowel movements for several months due to self-diagnosed irritable bowel syndrome. He also reported alcohol use of 4-6 beers 1-2 times a week for years. The patient was admitted for potassium and magnesium intravenous replacement. Chest $\mathrm{x}$-ray, magnetic resonance imaging of the cervical spine, computed tomography scan of the brain, and drug panel were all negative.

On day 1 of hospital stay the patient's electrolyte levels improved, with potassium of $3.6 \mathrm{mmol} / \mathrm{L}$ magnesium of $1.8 \mathrm{mg} / \mathrm{dL}$, phosphate of $4.0 \mathrm{mg} / \mathrm{dL}$, and calcium of $8.9 \mathrm{mg} / \mathrm{dL}$. On day 2, he reported improved strength. His labs indicated potassium of $3.6 \mathrm{mmol} / \mathrm{L}$, magnesium of $1.8 \mathrm{mg} / \mathrm{dL}$, phosphate of $5.0 \mathrm{mg} / \mathrm{dL}$, and calcium of $9.3 \mathrm{mg} / \mathrm{dL}$. His SARS-CoV2 antigen, blood, 
and urine cultures were all negative. A negative tissue transglutaminase $\lg A$ test ruled out celiac disease. On day 3 , potassium was $4.4 \mathrm{mmol} / \mathrm{L}$, magnesium was $1.7 \mathrm{mg} / \mathrm{dL}$, and a newly elevated phosphate of $5.7 \mathrm{mg} / \mathrm{dL}$ was noted. Calcium was $9.0 \mathrm{mg} / \mathrm{dL}$. Right arm edema and pain at the PICC line site prompted removal of the line; an ultrasound showed an occlusive deep venous thrombosis (DVT). A heparin drip was ordered, and a V/Q scan was negative. An asymptomatic run of ventricular tachycardia prompted an echocardiogram and troponin measurement, but both were negative.

On day 4 his labs revealed a low TSH of $<0.01 \mathrm{mlU} / \mathrm{L}$ and hypomagnesemia of $1.8 \mathrm{mg} / \mathrm{dL}$. Potassium was within normal limits. Phosphate was still elevated at $5.5 \mathrm{mg} / \mathrm{dL}$ and calcium was $10.0 \mathrm{mg} / \mathrm{dL}$. On day $5 \mathrm{a}$ low TSH of $<0.01 \mathrm{mIU} / \mathrm{L}$ was confirmed again; elevated T3 $9.99 \mathrm{pg} / \mathrm{ml}$ and T4 $2.86 \mathrm{ng} / \mathrm{dL}$ were also noted. His potassium at this time was $4 \mathrm{mmol} / \mathrm{L}$, magnesium was within normal limits, and phosphate was elevated at $7.0 \mathrm{mg} / \mathrm{dL}$ with calcium of $9.5 \mathrm{mg} / \mathrm{dL}$ and PTH of $36.7 \mathrm{pg} / \mathrm{mL}$ (normal <65). Ventricular tachycardia was attributed to hyperthyroidism, and a diagnosis of thyrotoxic periodic paralysis was made. An ultrasound of the neck showed a hypervascular thyroid consistent with Graves' disease or thyroiditis, and methimazole was started at a dose of $10 \mathrm{mg} 3$ times daily. On day 6 , a potassium of $3.8 \mathrm{mmol} / \mathrm{L}$, phosphate of $6.2 \mathrm{mg} / \mathrm{dL}$, calcium of $9.6 \mathrm{mg} / \mathrm{dL}$ and a magnesium of $2.3 \mathrm{mg} / \mathrm{dL}$ were recorded, and atenolol was started at a dose of $50 \mathrm{mg}$ twice daily. He was discharged home feeling well.

\section{Discussion}

Although rare, TPP is a severe and life-threatening complication of hyperthyroidism associated with thyrotoxicosis, acute paralysis, and hypokalemia. ${ }^{4}$ It is thought to be secondary to stimulation of the Na-KATP pump by thyroid hormone interaction with thyroid response elements (TRE), resulting in increased intracellular potassium and subsequent hypokalemia, usually $<3 \mathrm{mmol} / \mathrm{L}$. Other characteristic features of TPP include mild hypomagnesemia $(1.65+/-0.1 \mathrm{mg} / \mathrm{dL})$ and hypophosphatemia $(1.89+/-0.71 \mathrm{mg} / \mathrm{dL}){ }^{5}$

In a retrospective study of patients with TPP, hypophosphatemia occurred in $80 \%$ of the patients. ${ }^{5}$ This is due to a transcellular shift of the electrolytes. ${ }^{4}$ In fact, a urine calcium/phosphate ratio of $>1.4$ has been shown to detect TPP with a sensitivity of $100 \% .{ }^{6}$ Our patient's urine calcium levels were not obtained; however, his phosphate levels were monitored throughout his hospital course. Although the traditional TPP presentation is accompanied by hypophosphatemia, our patient presented with an unusual hyperphosphatemia. His levels increased throughout his stay from $4.0 \mathrm{mg} / \mathrm{dL}$ on hospital day 1 to $7.0 \mathrm{mg} / \mathrm{dL}$ on hospital day 5 . These levels slowly decreased to 5.9 at time of discharge after methimazole administration. A possible explanation for the mechanism of hyperphosphatemia is an increase in bone absorption stimulated by triiodothyronine secondary to hyperthyroidism. ${ }^{7}$

Hypomagnesemia is a common accompanying electrolyte abnormality of TPP due to the resulting transcellular shift of electrolytes. ${ }^{4}$ In a study with 24 patients, mild hypomagnesemia was noted in all patients during paralysis and was distinguished as a characteristic feature of TPP. ${ }^{5}$ Our patient drank a 12 pack of beer a week. Heavy alcohol intake is associated with depleted levels of total body magnesium. ${ }^{8}$ The severe hypomagnesemia controlled by several infusions during his hospital course was possibly exacerbated by his past alcohol use and his acute TPP. Due to preexisting alcohol use, his magnesium levels continued to stay low or borderline normal despite repeated replacement.

Studies have shown that hyperthyroidism is associated with a shift towards hypercoagulability in a dose-response manner. ${ }^{9}$ One proposed mechanism of this effect is by way of the thyroid hormone receptor $\beta$ affecting gene transcription of coagulation and fibrinolytic proteins. ${ }^{10}$ Another possible mechanism is via altered clot structure/lysis, as hyperthyroidism has been associated with increased density of clots and resistance to clot lysis. ${ }^{11}$ These effects normalize after return to a euthyroid state. Although the mechanism is unclear, it appears that thyroid hormone interacts with the coagulation system, resulting in increased levels of von Willebrand Factor and Factor VIII. Interestingly, the converse has also been shown to be true, with hypothyroidism associated with hypocoagulability and hyperfibrinolysis. Our patient demonstrated hypercoagulability causing right upper extremity DVT. ${ }^{9}$

Hyperthyroidism is associated with an increased risk of cardiovascular complications, such as atrial 
fibrillation and cardioembolic stroke. Cerebral arterial and venous thrombosis have also been frequently reported in hyperthyroid patients, and free T4 levels has been correlated with an increased risk of VTE. ${ }^{11}$ Although cerebral venous thrombosis and one case of lower extremity DVT have been reported, this is the first reported case of upper extremity DVT in association with a PICC line secondary to thyrotoxicosis. The incidence of DVT in association with PICC lines in an inpatient setting was found to be $8 \%$ with a median time to catheter related DVT of 55 days indicating that our patient's event occurred much earlier than expected based on information in the literature. ${ }^{12}$

\section{Conclusion}

Our patient demonstrated an unusual presentation of TPP with hyperphosphatemia, upper extremity DVT, and severe hypomagnesemia. The latter made the replacement of hypokalemia challenging. It is possible that the long-term alcohol use produced concomitant renal tubular losses of magnesium. These electrolyte derangements have precipitated potentially life threatening ventricular tachycardia. Also, upper extremity DVT can cause a potentially life threatening pulmonary embolism. Clinicians should be aware of this atypical presentation of TPP.

Article citation: Rahesh J, Al-Sukhni L, Quraishi B, Naguib T. Upper extremity deep venous thrombosis secondary to thyrotoxic periodic paralysis with accompanying hyperphosphatemia and severe hypomagnesemia. The Southwest Respiratory and Critical Care Chronicles 2021;9(41):47-49

From: Department of Internal Medicine, Texas Tech University Health Sciences Center, Amarillo, Texas

Submitted: $8 / 17 / 2021$

Accepted: 9/24/2021

Reviewer: Shaili Felton MD

Confiicts of interest: none

This work is licensed under a Creative Commons Attribution-Share A like 4.0 International License.

\section{REFERENCES}

1. Lam L, Nair RJ, Tingle L. Thyrotoxic periodic paralysis. Proc (Bayl Univ Med Cent) 2006;19(2):126-129. doi:10.10 80/08998280.2006.11928143

2. O’brien JC. History of tumor site conferences at Baylor University Medical Center Proc 2006;19(2):130-131.

3. Siddamreddy S, Dandu VH. Thyrotoxic periodic paralysis. In: StatPearls. Treasure Island (FL): StatPearls Publishing; July 26, 2020 .

4. Garla VV, Gunturu M, Kovvuru KR, et al. Thyrotoxic periodic paralysis: case report and review of the literature. Electron Physician 2018;10(8):7174-7179.

5. Manoukian MA, Foote JA, Crapo LM. Clinical and metabolic features of thyrotoxic periodic paralysis in 24 episodes. Arch Intern Med 1999;159(6):601-606.

6. Lin SH, Chu P, Cheng CJ, et al. Early diagnosis of thyrotoxic periodic paralysis: spot urine calcium to phosphate ratio. Crit Care Med 2006;34(12):2984-2989.

7. Wang XB, Chao CS, Wu HW, et al. [Hypercalcemia and hyperphosphatemia in thyrotoxoicosis and the therapeutic effect of propranolol, in Chinese]. Zhonghua Nei Ke Za Zhi 1989;28(11):646-699.

8. Vandemergel X, Simon F. Evolution of metabolic abnormalities in alcoholic patients during withdrawal. J Addict 2015; 2015:541536. doi:10.1155/2015/541536

9. Elbers LPB, Fliers E, Cannegieter SC. The influence of thyroid function on the coagulation system and its clinical consequences. J Thromb Haemost 2018;16(4):634-645.

10. Kim TY, Ihm SH, Roh JW, Lim S, Park CS, Kim HY. Massive pulmonary thromboembolism combined with transient thyrotoxicosis in an 18-year-old girl. Clin Hypertens 2020; 26:17. Published 2020 Sep 1. doi:10.1186/s40885-02000150-2

11. Hooper JM, Stuijver DJ, Orme SM, et al. Thyroid dysfunction and fibrin network structure: a mechanism for increased thrombotic risk in hyperthyroid individuals. J Clin Endocrinol Metab 2012;97(5):1463-1473.

12. Taxbro K, Hammarskjöld F, Thelin B, et al. Clinical impact of peripherally inserted central catheters vs implanted port catheters in patients with cancer: an open-label, randomised, two-centre trial. Br J Anaesth 2019;122(6):734-741. 